\title{
Multiple accessory left atrial appendages on cardiac computed tomography
}

\author{
Shu Yoshihara' ${ }^{1}$ Taku Yaegashi², Masaki Matsunaga ${ }^{3}$, Masaaki Naito'
}

'Department of Diagnostic Radiology, Iwata City Hospital, Iwata, Japan

2Department of Radiological Technology, Iwata City Hospital, Iwata, Japan

${ }^{3}$ Department of Cardiology, Iwata City Hospital, Iwata, Japan

\author{
Correspondence to: \\ Shu Yoshihara, MD, PhD, \\ Department of Diagnostic \\ Radiology, Iwata City \\ Hospital, \\ 512-3 Ookubo, Iwata, \\ 438-8550, Japan, \\ phone: +81538385000, \\ e-mail: \\ shuy@hospital.iwata. \\ shizuoka.jp \\ Copyright by the Author(s), \\ 2021 \\ Kardiol Pol. 2021; \\ 79 (7-8): 881-882; \\ DOI: 10.33963/KP.a2021.0007 \\ Received: \\ April 11, 2021 \\ Revision accepted: \\ April 29, 2021 \\ Published online: \\ May 13, 2021
}

A 67-year-old man with a history of diabetes mellitus and paroxysmal atrial fibrillation (AF) was referred for cardiac computed tomography (CCT). CCT showed significant stenosis in the left circumflex coronary artery (Figure 1A, black arrow). He had a left atrial appendage (LAA) with ostium dimensions of $26 \mathrm{~mm}$ by $14 \mathrm{~mm}$ (Figure 1, Supplementary material, Figure S1A). In addition, he had three accessory LAAs along the left atrioventricular groove under the LAA (Figure 1, Supplementary material, Figure $S 1 B-D$ ). The accessory LAA ostium dimensions were $20 \mathrm{~mm}$ by $10 \mathrm{~mm}$ (arrow), $11 \mathrm{~mm}$ by $8 \mathrm{~mm}$ (arrowhead), and $12 \mathrm{~mm}$ by $7 \mathrm{~mm}$ (asterisk). No definite thrombus was found inside these accessory LAAs.

The true prevalence of accessory LAAs is not clear. Üçerler et al. [1] reported the presence of cauliflower type accessory LAA in one specimen in a study of 56 normal autopsy hearts. In contrast, focal outpouchings of the LA wall are frequently found on CCT. In previous reports, accessory LAAs have been defined as outpouchings showing a discernible ostium with a neck and body displaying irregular contours suggestive of pectinate muscles, like our case, while LA diverticula are defined as outpouchings having a saclike structure with a broad-based ostium and a smooth body contour [2]. Patients with multiple LA diverticula are occasionally found [3]. By contrast, patient with multiple accessory LAAs is extremely rare [3]. Accessory LAAs and LA diverticula can cause serious complications during catheter ablation, as they may be sites of catheter entrapment with a risk of LA wall perforation. Although ectopic electrical activity and thrombus formation have been described in patients with accessory LAAs and
LA diverticula, the exact relation between these LA abnormalities and atrial arrhythmias or thromboembolic events remains uncertain [2, 3]. However, some reports indicate that a single accessory LAA and LA diverticulum could be a source of thromboembolism [2,4]. Outpouching with the presence of trabeculation within it may promote thrombus formation through the mechanism of blood stasis in patients with AF. The theoretical risk of thrombosis within accessory LAAs will be higher in individuals with multiple accessory LAAs than those with a single accessory LAA. Recently, percutaneous LAA closure has emerged as an alternative to oral anticoagulation for stroke prophylaxis in nonvalvular AF patients with increased bleeding risk [5]. Based on existing randomized controlled trials as well as multiple observational studies, the safety and feasibility of LAA closure devices continue to improve. It is important to have a thorough understanding of the LAA's anatomy and neighboring cardiac structures around the LAA by preprocedural cardiac imaging to achieve optimal procedural outcomes and avoid intraprocedural and postprocedural complications. Multiple accessory LAAs should be recognized before interventional procedures such as percutaneous LAA closure or AF catheter ablation, because it may alter clinical decision making.

\section{Supplementary material}

Supplementary material is available at https:// journals.viamedica.pl/kardiologia_polska.

\section{Article information}

Conflict of interest: None declared.

Open access: This article is available in open access under Creative Common Attribution-Non-Commercial-No 

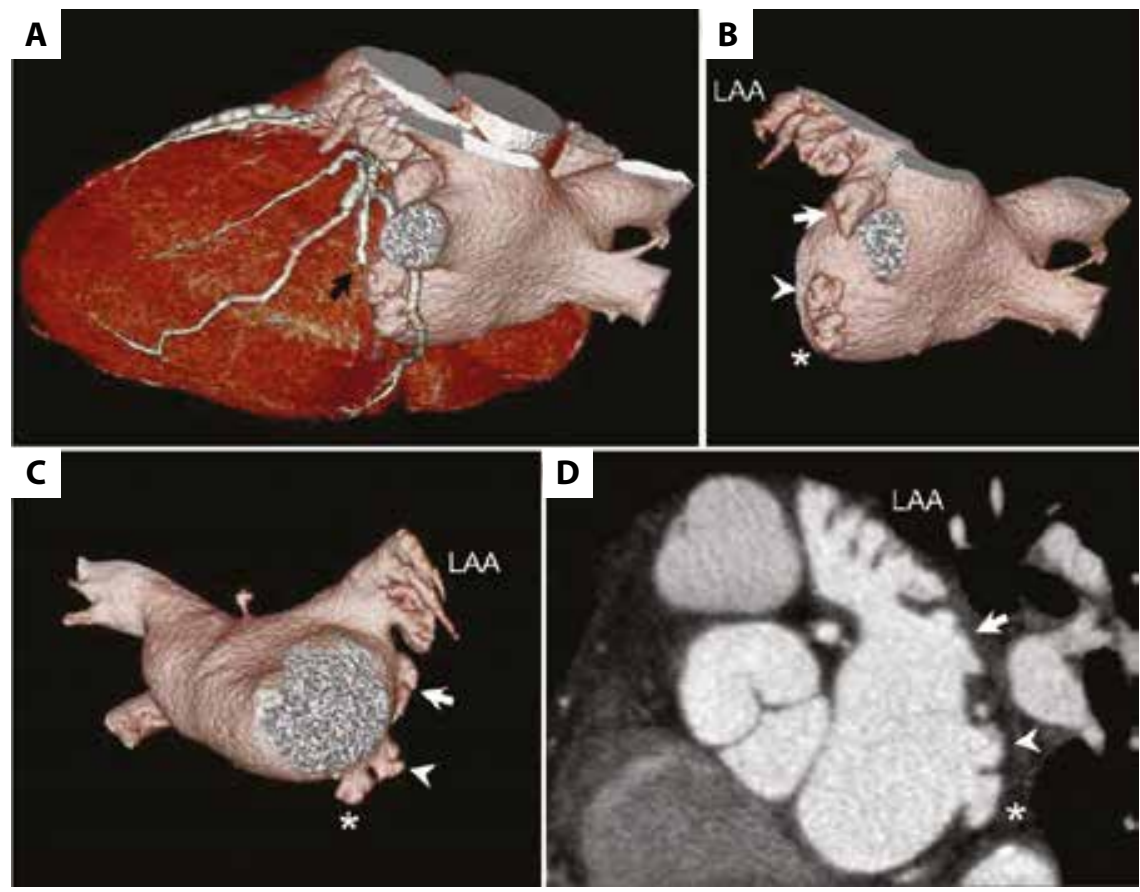

Figure 1. A. Left posterior oblique view of three-dimensional volume-rendered reconstruction image of cardiac computed tomography showing significant stenosis in the left circumflex coronary artery (black arrow). B. and C. Three-dimensional volume-rendered reconstruction images of cardiac computed tomography showing three accessory left atrial appendages along the left atrioventricular groove under the left atrial appendage (LAA) (arrow, arrowhead, asterisk); B. Left posterior oblique view. C. Left anterior oblique view. D. Curved multiplanar reconstruction cardiac computed tomography image of the left lateral left atrial wall showing three accessory left atrial appendages along the left atrioventricular groove under the LAA (arrow, arrowhead, asterisk)

Derivatives 4.0 International (CC BY-NC-ND 4.0) license, allowing to download articles and share them with others as long as they credit the authors and the publisher, but without permission to change them in any way or use them commercially. For commercial use, please contact the journal office at kardiologiapolska@ptkardio.pl.

How to cite: Yoshihara S, Yaegashi T, Matsunaga M, et al. Multiple accessory left atrial appendages on cardiac computed tomography. Kardiol Pol. 2021; 79(7-8): 881-882, doi: 10.33963/KP.a2021.0007.

\section{REFERENCES}

1. Üçerler $\mathrm{H}$, İkiz ZA, Özgür T. Human left atrial appendage anatomy and overview of its clinical significance. Anadolu Kardiyol Derg. 2013; 13(6): 566-572, doi: 10.5152/akd.2013.181, indexed in Pubmed: 23886901.

2. Hołda MK, Koziej M, Wszołek K, et al. Left atrial accessory appendages, diverticula, and left-sided septal pouch in multi-slice computed tomogra- phy. Association with atrial fibrillation and cerebrovascular accidents. Int J Cardiol. 2017; 244: 163-168, doi: 10.1016/j.ijcard.2017.06.042, indexed in Pubmed: 28629626.

3. Lazoura O, Reddy T, Shriharan M, et al. Prevalence of left atrial anatomical abnormalities in patients with recurrent atrial fibrillation compared with patients in sinus rhythm using multi-slice CT. J Cardiovasc Comput Tomogr. 2012; 6(4): 268-273, doi: 10.1016/j.jcct.2012.02.004, indexed in Pubmed: 22732200

4. Nagai T, Fujii A, Nishimura K, et al. Large thrombus originating from left atrial diverticulum: a new concern for catheter ablation of atrial fibrillation. Circulation. 2011; 124(9): 1086-1088, doi: 10.1161/CIRCULATIONAHA. 110.000315 , indexed in Pubmed: 21875923.

5. Cruz-González I, Trejo-Velasco B. Percutaneous left atrial appendage occlusion in the current practice. Kardiol Pol. 2021; 79(3): 255-268, doi: 10.33963/KP.15864, indexed in Pubmed: 33687872. 